\title{
The Case for Natural History
}

King, Heather; Achiam, Marianne

Published in:

Science \& Education

DOI:

10.1007/s11191-017-9880-8

Publication date:

2017

\section{Document version}

Peer reviewed version

Document license:

Unspecified

Citation for published version (APA):

King, H., \& Achiam, M. (2017). The Case for Natural History. Science \& Education, 26(1-2), 125-139. https://doi.org/10.1007/s11191-017-9880-8 


\section{The Case for Natural History}

Heather King ${ }^{1} \&$ Marianne Achiam*2

*Corresponding author: Marianne Achiam, achiam@ind.ku.dk, +4535320357

${ }^{1}$ Department of Education and Professional Studies, King's College London, FranklinWilkins Building, Waterloo Road, London, SE1 9NH, United Kingdom

${ }^{2}$ Department of Science Education, University of Copenhagen, Øster Voldgade 3, 1350 Copenhagen, Denmark

Fundamental knowledge of natural history is lacking in many western societies, as demonstrated by its absence in school science curricula. And yet to meet local and global challenges such as environmental degradation, biodiversity loss and climate change, we need to better understand the living and non-living parts of the natural world. Many have argued passionately for an increased understanding of natural history; others have developed successful pedagogical programmes for applying a knowledge of natural history in environmental initiatives. In joining wider calls, we choose here to focus on the educational value afforded by understanding the epistemological bases of natural history and its particular forms of reasoning. We also briefly discuss the ways in which an education in natural history provides the foundation for environmental and social justice efforts that directly affect the lives of young people and their communities. We end by highlighting the ease by which natural history may be incorporated in learning opportunities both in and outside of the classroom.

\section{Introduction}

We do not appreciate the natural world. For much of our daily existence - in school, at work, in our homes - we pay it little regard. As Trombulak and Fleischner $(2007$, p. 1) have insightfully observed: "We now live in a world where it matters more whether it is a Friday or a Saturday than if it is autumn or winter." And yet, beyond the bubble of our increasingly non-nature based lives, there are key issues facing society that need to be acknowledged. At the global level, these include climate change, food security and inequities within and between nations. At a more local level, issues include environmental degradation, biodiversity loss, and pollution. In order to face these challenges, and determine the best possible paths of action, we need to understand the processes that shape the both the living and non-living parts of the natural world. As Tewksbury et al. (2014) powerfully argue, in order to make sense of changes to the Earth's ecosystems, we need a knowledge of organisms living now and in the geological past. We need to know what they are, where they live, what they eat, how they mate and how they die. In short, we need a knowledge of natural history.

Natural history has been defined in various ways. Many of these definitions consider natural history to be the detailed and direct observation of animals and plants in their natural settings (e.g. Greene, 1994; Greene \& Losos, 1988; Wilcove \& Eisner, 2000). This 
observation involves understanding aspects of the physical environment in which the animals and plants live, but also of their evolutionary history. Accordingly, most definitions of natural history acknowledge that it also embraces the study of historical life forms in the shape of fossil evidence (e.g. Bartholomew, 1986; Fleischner, 2005).

We would argue that natural history is the foundation of the modern disciplines of ecology, evolutionary biology and animal behaviour. Like Arnold (2003), we perceive natural history to be a robust and thriving enterprise, and one which also lives through its descendant disciplines. Others, however, (Greene, 2005; Halfpenny \& Ozanne, 1989) consider natural history to be an endeavour that is distinct from more recent branches of study on the basis of it being mainly non-manipulative, descriptive and comparative. And herein lies the key challenge for advocates of natural history. While its descriptive and comparative language provides the backdrop against which the interconnectedness of animals, plants, and environment can be understood (Fleischner, 2005; Futuyma, 1998), its non-manipulative nature leaves natural history vulnerable to neglect in academia due to scientific elitism and the overemphasis on hypothesis testing (Dayton, 2003; Greene, 2005).

Our focus in this article is to highlight the value of a natural history education for a rounded understanding of science. Although we acknowledge that many biology curricula support student identification of living forms and processes, we would argue that this is not enough. An education in natural history comprises both a detailed knowledge of plants and animals in their natural environment now and in the past, and an understanding of the scientific reasoning processes and practices through which the discipline proceeds. As a result, learners will be equipped with the knowledge, skills and reasoning abilities to be able to actively participate in discussions and initiatives relating to highly complex environmental and social justice issues facing contemporary society.

We begin by outlining the nature of natural history and the forms of reasoning which it employs. In so doing we argue that its epistemological bases are just as valid as those grounded in experimentation. Next, we discuss how a strong understanding of natural history equips individuals and communities with the tools needed to make a difference in their lives. Finally, we discuss potential obstacles for the implementation of natural history education and offer some solutions, both inside and outside the classroom.

\section{The Nature of Natural History and its Forms of Reasoning}

In the following, we discuss the distinguishing features of natural history, and in so doing make comparisons with the features of other natural sciences. We use elements of Kuhn's disciplinary matrix (Kuhn, 1977; see also Bird, 2013) to structure this discussion, using objects and systems of research, experimental techniques, values, and forms of reasoning to describe natural history and contrast it with other sciences.

\subsection{Objects and systems of research}

Natural history focuses on living systems. These systems are necessarily open and as such subject to multiple interactions, variation and chance phenomena. Furthermore, research shows that living things are governed by a complex interaction between their genetic composition, the physical expression of that genetic composition or phenotype, and the 
environment (Lewontin, 2002). This introduces a level of unpredictability which precludes natural history from working with precise models. Even if a living system were to be isolated with certain aspects controlled, it would need to be removed from its natural state, thus throwing into doubt the applicability of any conclusions made. As a result, such studies are less able to be repeated and thus less likely to demonstrate any universal laws, although findings can indicate a tendency or probability of future events.

This contrasts with the sciences that work with closed systems. In closed systems, once the governing laws are identified, they will always apply. In such cases, the generation of new knowledge involves the manipulation of variables and repeated experimentation leading to the development of models and the prediction of future events.

\subsection{Experimental techniques}

Natural history involves proposing relationships based upon comparisons of extant specimens, which in turn depends upon detailed observations of such specimens. In proposing such relationships, natural historians work within the theoretical framework of evolutionary biology and apply the methodological framework of cladistics - that is groupings, or clades, of organisms are identified based on their recency of common descent as judged by the possession of shared derived characteristics. Identifications and claims for phylogenetic relationships are increasingly based upon genetic analyses, however most initial analyses are made at the level of the phenotype and involve the use of observational tools. A specimen is closely observed and compared with others, whereupon a classification for the specimen, or a speculation on a function of a feature (or behaviour) or the living organism given its form, is proposed. In addition to the observation of morphological or physiological traits, the observation may also extend to an examination of the products of the organism's behaviour, such as the shape of its nest (Mayr, 2004). In observing specimens carefully and recording such observations, and thereafter comparing the specimen with other known specimens, the natural historian is constructing a body of data and establishing patterns of evidence.

As previously noted, the nature of natural history as a non-experimental science causes some researchers to dismiss it as unscientific. However, the fact is that most scientific disciplines utilise experimentation to varying degrees. In discussing the role of the experiment in the natural sciences, Brandon (1994) describes the space of experimentality as formed by two continua (test/don't test hypothesis and manipulate/don't manipulate variable). While natural history is clearly limited to one area of this space of experimentality (don't test hypothesis and don't manipulate variable), we note that other scientific disciplines avail themselves of a variety of methods and procedures, some that explicitly test hypotheses, others that don't; some that can and do manipulate variables and others that can't and thus don't. We therefore observe that there is nothing about the way natural history produces knowledge that can be a priori evaluated as being of less significance than other forms of knowledge production (see Rose, 2005).

\subsection{Values}


A key focus of natural history is interpreting the causes of past phenomena. In these cases, natural history cannot rely on in-situ observation, or engage in experimentation. Instead, the emphasis is on interpreting complex causal chains that occurred over long periods of time, simply by using traces of evidence that remain. The fact that the event took place in the past, in addition to the fact that the phenomena are complex, unique and contingent, means that tests of validity lie solely in the quality of the explanation generated through abductive reasoning. In other words, effective explanation is valued in natural history (Gray, 2014).

Generating explanations of this kind involves combining many objects, observations, and other types of evidence, both for and against the hypothesis in question. The process of holding these types of evidence up against one another requires scientific ways of reasoning that go beyond those familiar from the more experimental sciences. In the following section, we discuss the forms of reasoning that are prevalent in natural history.

\subsection{Forms of reasoning}

\subsubsection{Abductive reasoning}

The most prevalent form of reasoning employed in natural history is abductive reasoning. In abductive reasoning, observations precede hypotheses but do not necessitate them. Rather, abductive reasoning uses observations to develop a set of explanations that are most logical and parsimonious, and infers theory from them. In short, abduction examines the effect to determine the cause:

Because B, therefore A.

Logically, of course, the abductive reasoning approach is flawed. There may, after all, be several explanations (theories) for an outcome B. However, science based on abductive reasoning is not a stab in the dark. Rather, the development of explanations proceeds through a dialogue of critique and refinement. Science has a clear methodology for assessing explanations and for adjudicating between competing ideas, and only the most reasonable stand the test of time. A consensus emerges after alternative explanations are found to be wanting.

An example of understanding stemming from abductive reasoning may be found in a study related to dinosaur morphology. In seeking to determine the neck posture of sauropod dinosaurs, researchers must interpret anatomy from an incomplete fossil record. In previous reconstructions of the sauropod body plan, researchers have proposed an upward sloping curve for the neck (see Christian \& Dzemski, 2007); others have posited a straight, horizontal or downward curving sloping neck (Stevens \& Parrish, 1999). Yet others (Taylor et al., 2009) have argued that sauropods held their necks extended with their heads flexed such that the mid-cervical region was near vertical. All these perspectives build upon interpretations of the available evidence. The researchers also seek to support their claims by invoking related 
findings and theory. In particular, Taylor et al. (2009) emphasised the evolutionary basis of phylogenetic relationships between extinct and extant animal groups to develop their claim. They argued that given the evolutionary relationship between species within particular evolutionary groups or clades a similarity must exist between the neck structure of extinct sauropods and that of mammals, turtles, crocodilians and birds alive today. Finally, and as is common in all scientific disciplines, the researchers defend their claim on grounds of parsimony:

It is most parsimonious to assume that the necks of sauropods were supported by the same mechanisms as in their extant outgroups, and in similar postures... When considering the lifestyles of extinct animals, those of their extant relatives remain the best guide (Taylor et al., 2009, p. 219).

Accordingly, we argue that just like other forms of scientific reasoning, abduction has its own well-tested ways of arriving at valid scientific claims.

\subsubsection{Inductive and retrodictive reasoning}

A related form of reasoning is that of inductive reasoning. As in abduction, inductive reasoning begins with observations that in turn lead to hypotheses. However, it differs from abductive reasoning in that the generation of a theory is not required. Rather, inductive reasoning represents a strong probability. In abduction there is an implicit or explicit appeal to explanatory considerations, whereas in induction there is only an appeal to observed frequencies or statistics.

An example of inductive reasoning is provided by Dansgaard et al. (1993). These researchers used the Greenland ice sheet as a historical document, due to the successive layers of ice having trapped air from the Earth's atmosphere over several hundred thousand years. In polar glacial ice, the ratio between the oxygen isotopes ${ }^{18} \mathrm{O}$ and ${ }^{16} \mathrm{O}$ is mainly determined by the temperature at which it is formed. This means that based on the ratio of ${ }^{18} \mathrm{O} /{ }^{16} \mathrm{O}$ in air trapped at various depths of the ice sheet, Dansgaard et al. were able to hypothesise the presence of several periods of climate instability in the past 230,000 years.

Closely related to inductive reasoning is retrodictive reasoning: predicting that something happened in the past, although there may not yet be visible evidence for this. The work of Darwin offers an oft-cited example of retrodiction. Darwin retrodictively reasoned that intermediate fossil forms of life would be found in the future thus substantiating his proposal of evolution by natural selection (Schopf, 2000). Such fossil forms were indeed subsequently found, e.g. Archaeopteryx, which showed traits of both non-avian dinosaurs and birds (Huxley, 1868) and Tiktaalik, which showed primitive fish traits as well as derived tetrapod traits (Daeschler et al., 2006).

\subsubsection{Hypothetico-deductive reasoning}

Hypothetico-deductive reasoning forms the basis of process in the physical sciences. It also has a role in the discipline of natural history, although this role is secondary to initial abductive reasoning. Hypothetico-deductive reasoning involves the development of a 
hypothesis to explore and test a proposed reason for an observation. This hypothesis predicts a particular set of outcomes. The validity of the hypothesis can then be determined by testing whether the outcomes do indeed materialise. If the outcomes are observed, and the hypothesis is validated, the wider theory (in the light of which the hypothesis was generated) is supported. If the outcomes are not observed, the hypothesis is rejected. The relative strength of the underpinning theory, meanwhile, is determined by comparing how well its constituent hypotheses are corroborated by the results of their predictions. In short, if $\mathrm{A}$ is the theory, and B is the outcomes, hypothetico-deductive reasoning can be expressed as:

Because A, therefore B.

If $B$ found, $A$ is validated.

If $\mathrm{B}$ not found, $\mathrm{A}$ is rejected.

A classic and early example of the hypothetico-deductive approach, is provided in the work of the $17^{\text {th }}$ Century Italian naturalist and physician Francesco Redi who, in observing the nature of meat left out in the air, hypothesised that infesting worms hatched from eggs laid by flies rather than generating spontaneously as a result of the decomposition process. Redi described his hypothesis and subsequent experiment:

I began to believe that all worms found in meat were derived directly from the droppings of flies, and not from the putrefaction of the meat, and I was still more confirmed in this belief by having observed that, before the meat grew wormy, flies had hovered over it, of the same kind as those that later bred in it. Belief would be vain without the confirmation of experiment, hence in the middle of July I put a snake, some fish, some eels of the Arno, and a slice of milk-fed veal in four large, wide-mouthed flasks; having well closed and sealed them. I then filled the same number of flasks in the same way, only leaving these open. It was not long before the meat and the fish, in these second vessels, became wormy and flies were seen entering and leaving at will; but in the closed flasks I did not see a worm, though many days had passed since the dead flesh had been put in them (Redi, 1688/1909, p. 33).

In practice, natural historians use many forms of reasoning in their work. For example, upon discovering a number of specimens to allow for a viable population, one could inductively reason that this was a new species. To determine whether the specimens were genetically distinct, hypothetico-deductive reasoning would shape the design of the necessary experiment. Abductive reasoning, however, would be employed to explain how the new species evolved and how it should be classified.

In summary, we have described the disciplinary matrix of natural history and in particular highlighted the emphasis placed on abductive, retrodictive and inductive reasoning. In the final sections, we return to the argument that natural history offers a much-needed opportunity for learners to engage with forms of scientific reasoning that stretch beyond the hypothetico-deductive approaches which currently pre-dominate in school curricula. But firstly, we turn to a broader discussion explaining the import of an education in natural history. 


\section{The Value of an Education in Natural History}

In this section of the article, we suggest that an education in natural history provides a foundation for many initiatives concerned with environmental and social justice. Indeed, we suggest that a greater knowledge of natural history and, in particular, the names of and ecological relationships between plants and animals in one's neighbourhood is consistent with, and supportive of, efforts aimed at reducing inequities across society. Specifically, we argue that an understanding of natural history is vital in resolving issues of localised biodegradation and biodiversity loss, which in turn contribute to global issues of food security, disease control and climate change.

Social justice calls for a shared and common humanity, and the fair allocation of community resources. Given that human life is inextricably linked to its environment, it follows that if common humanity is to thrive, the resource-providing environment must be respected, protected and used equitably (Miller, 2005). To ensure sustainable use of the natural environment, an understanding of local natural history is fundamental. At a very basic level, we are more likely to value something if it has a name and if we have experienced it (Chawla, 1998). But the argument of natural history for social justice applies beyond more immediate instances of sustainably harvesting food and raw materials. A knowledge of natural history, and its descendant discipline of environmental science, can also support social justice initiatives in inner city environments as exemplified by the Green Technologies in the City (GET City) programme discussed by Calabrese Barton and Tan (2010). For example, in their work examining the actions of youth engaged in an initiative to research and redress urban heat islands, the researchers (Calabrese Barton \&Tan, 2010) found that young peoples' new understanding of native species of tree that could potentially thrive in the climate of the Mid-West city provided them with key knowledge, which they then used in information and campaign materials. In short, a knowledge of natural history served to increase their agency in community issues.

The foundational nature of an education in natural history is further exemplified by its role as a central pillar in place-based education (Hutchinson, 2004; Sobel, 2008). Place-based education calls for a multidimensional understanding of place and highlights the ways in which a knowledge of the natural environment intersects with everyday experiences of community life. Furthermore, it advocates the need to equip learners with the skills to act for both the social and the ecological places in which they live (Gruenewald, 2003). A study illustrating the intersection between community well-being and knowledge of one's environment is provided by Carlone et al. (2015). In this study, the authors followed 16 high school students from diverse backgrounds as they participated in a four-week summer enrichment programme focussed on herpetology - the study of reptiles and amphibians. The students were trained to trap, handle and identify local species to map population type and density. They also learnt about the ecology of the animals and the nature of the habitats in which they lived. The paper is framed by the premise that it is essential for young people to understand their environment and its flora and fauna in order to address local (and global) problems such as ensuring safe and affordable food, and combatting environmental 
degradation. In this way, we suggest that in addition to the paper being a study of how best to structure a youth enrichment programme, it also describes the process of engagement in natural history for the outcome of social justice. In being able to name local species the students gained an understanding of ecological relationships and the nature of the wider environment. This in turn will have equipped students with the background knowledge and skillset to participate in environmental and community issues, and potentially raise questions about inequalities of access, of ownership, and of power.

A knowledge of natural history similarly underscores other social justice movements including campaigns for indigenous rights and culturally relevant pedagogy (Ladson-Billings, 1995), and community renewal. Hamlin (2013), for example, notes the value of connecting traditional ecological knowledge with formal, Western-orientated curricula to empower marginalized communities. Douglas and Katz (2009), meanwhile, describe a zoo-based programme focused on issues of animal care and conservation following which learners expressed strong interest in taking action for the environment in their own neighbourhoods.

The studies summarized above affirm the benefits of an education in natural history to equip young people with the knowledge and skills to engage knowledgeably about local issues, most of which will inevitably involve aspects of the physical and biological local environment. In the final section of the article, we discuss the current lack of education in natural history, before going on to discuss ways in which greater support for natural history education may be afforded.

\section{The Obstacles facing Natural History Education and how they can be Addressed.} Maxwell (2004) argued that that US National Research Council's Scientific Research in Education Report of 2002 emphasised the pre-eminence of randomized experiments. The situation subsequently has been little different (Grandy \& Duschl, 2005; Blachowicz, 2009). The Next Generation Science Standards (NGSS 2013) may be seen to represent a more realistic view of the epistemic practices of scientific disciplines, yet the experimental sciences are still prioritised in the examples provided. Thus, while some attention might be paid to the results of natural history research, the methodologies used to investigate phenomena and to generate results are rarely discussed (Gray, 2014). Research indicates that the situation may be similar in other parts of the world (Fisher, 2001; Orion \& Hofstein 1994; Piranha et al., 2011). This absence is a serious concern because as Gray and Kang (2014) have argued, those scientific methodologies that are left out are implied to be less legitimate.

At the level of both the primary and secondary classroom, curriculum emphases are manifested in the use of terms connected to the physical sciences such as predictions, experiments, controls and variables. Indeed, many school textbooks tend to assert that the validity of scientific knowledge is judged solely by its agreement with experimentally acquired evidence (Hodson, 2009). Other commentators have decried this pre-eminence on hypothetic-deductive reasoning on the basis that it may be contributing to the rejection of evolutionary theory. As Rudolph and Stewart (1998) have noted, evolution denouncers will often use the inability to test or replicate evolution as a reason for rejecting it. We argue that curricula should include a greater explication of the ways in which natural history proceeds - 
its methodological approaches, its forms of reasoning, and how its arguments and conclusions made are judged according to different standards (cf. Cleland, 2002, 2011; Forber \& Griffith, 2011). In creating more balanced curricula which give due weighting to natural history, learners' perceptions of the sciences noted by Taber (2014) as being experimental, monolithic and depersonalized will also be countered.

In addition, we suggest that in highlighting the guiding theoretical framework of cladistics in proposing relationships between species, the practice of natural history would help students to understand the defining principle of scientific practice. As Hodson (2009, 2014) has argued, science education is not about teaching students to observe, classify, measure, and hypothesise per se. Rather it is about engaging learners in scientific observation, scientific classification, scientific measurement and scientific hypothesizing, with the epithet of scientific resulting from the judicial selection of methods based on theory. The explicit reference to theory afforded by natural history is particularly important given research findings suggesting that few teachers (Gyllenplam et al., 2009) and few student teachers (Windschitl, 2002, 2003) recognise the significance of explanatory frameworks, or understand that scientific hypotheses are based on theoretical assumptions. Indeed, by highlighting theory, the practice of natural history will serve to link the domain of objects (i.e. natural history specimens) to the domain of ideas (evolutionary theory, and the methods of cladistics) in ways that Tiberghien (2000) and Abrahams and Millar (2008) have argued is often not addressed in schools.

In sum, the processes of natural history showcase the nature of abduction and the role of theory and thus provide a context for a more rounded education with respect to the practice and epistemology of science. As Lawson (2010) has argued, students need to reflect on hypotheses and 'exercise' their nascent inferential skills. They need to engage in all forms of reasoning in order to strengthen their ability to think and act scientifically. Given the import of impending environmental issues, one could argue that skills in abduction and inference will be particularly useful for students in the future. In the following, we outline the ways in which natural history may be readily adopted within classroom practice. We also highlight the resources provided by natural history museums for further advancing understanding of the discipline and the wider contexts to which it relates.

\subsection{In the classroom}

Greater practice of natural history in school is possible without recourse to expensive equipment or even laboratory settings. Moreover, lengthy periods of time are not needed, as the observation and comparison of species can occur across as little or as long a timeframe as available. In terms of equipment, most of the tools required for the practice of natural history - at least at the level of the phenotype - are relatively cheap and easy to obtain. Optical microscopes are useful in the observation of small organisms or parts of organisms, but hand lenses are often sufficient. Specimens may be collected locally in advance of the lesson, or by the students during the lesson. Other more exotic specimens (often as casts or models) may be bought relatively cheaply from education suppliers. With respect to pedagogical practice, we note simple prompts based on a series of question stems designed to encourage careful 
observation and then comparison have proved effective in scaffolding students' initial engagement with natural history specimens (King, 2009). For example, to prompt observation, exemplar questions include: "How many legs does it have? How would you describe the shape? Is there any symmetry? To prompt comparison, key questions would be: How are $\mathrm{X}$ and $\mathrm{Y}$ similar? How are $\mathrm{X}$ and $\mathrm{Y}$ different? To support students' understanding of the evolutionary framework underpinning phylogenetic grouping, key questions include: Given those comparisons, how would you group the specimens? And given your groupings, how do you think this organism moves/eats/etc.? Can you think of any animals [or plants] that are similar to this specimen? How would our knowledge of those animals help us to interpret this specimen?"

While acknowledging the possibility to stay simple and remain inside a classroom, many authors have noted the benefit to students of experiencing natural history in situ. As Louv (2006) has lamented, young people are becoming more and more disconnected from nature. In spending less time outdoors, and more time looking at screens (Pergams and Zaradic 2006, 2008; Rideout et al., 2010) young people have limited opportunities to directly explore nature. As a result, it is hardly surprising that children are more able to recognize videogame characters than common wildlife species (Balmford et al., 2002). We acknowledge that education providers are not solely responsible for ensuring access to natural environments, but wholeheartedly concur with the sentiments of Lorsbach and Jinks (2013, p. 13) who take policymakers to task and urge that standardized curricula and testing regimes "make room for children to go outside, dig up dandelions, and observe robins".

On studying the effects of learning outside the classroom, researchers (Amos \& Reiss 2012; Dillon \& Dickie, 2012; Davies et al., 2015) have pointed to gains in the affective, social/interpersonal, and physical/behavioural domains. Frøyland, Remmen and Sørvik (2016) observe that authentic geological observation had positive, long-term effects on students' scientific understanding. Nundy (1999) suggested that affective and social benefits of learning outside can accrue, and have a knock-on effect for, students' engagement with cognitive material at a later date. Indeed, researchers (Crowley et al., 2015) have found that participation in outdoor learning opportunities can be motivating for many students and help to reverse dissatisfaction with science back in the classroom. Bencze, Sperling and Carter (2012) suggest that practical work in real life contexts, and with an underlying social justice agenda, can also provide the answer to the oft-asked student question of "why are we learning this stuff?" Moreover, we note that the particular skills related to natural history activities specifically - that of observation, looking for patterns, justifying explanations (Eberbach \& Crowley, 2005) and also systems thinking (Wals, 2014) - are essentially the building blocks of all scientific thinking. In this way, we argue that engagement in the natural history can provide the foundation for scientific skills more broadly, and, particularly when conducted outside, enhance student motivation for science. In turn, an increase in confidence and in motivation can support the development of a science identity in students, which is key to their continued participation (Aschbacher et al., 2014; Carlone et al., 2015).

Finally, while we argue that the inclusion of natural history within science curricula is pragmatically possible, we accept that the opportunities for some students and teachers to 
explore and potentially critically shape their local environments can be "overwhelming, exhausting and hopeless idealistic" (Alsop and Bencze, 2012:396). However, here we would recommend starting small and gaining confidence in working in natural history contexts before extending the focus to issues of social and environmental justice. For example, Coskie, Hornof and Trudel (2007) found that following an activity to develop a field guide to identify plants in a small area of local woodland, students aged 8-10 began to feel responsible for their local environment, and were subsequently keen to learn more. We would also highlight the benefits of teaching natural history, particularly in context, for the morale of both teachers and students. For example, teachers have reported a better rapport with their students (Cramp, 2008), and moreover enjoy the experience of engaging in nature (Malone \& Waite, 2016; Peacock, 2006). Lorsbach and Jinks (2013) meanwhile cite Comstock's (1911) Handbook of Nature Study in which he argued that studying local organisms led to teachers being less didactic, dogmatic and tense! We end by acknowledging that the school day is not infinite, and that more natural history means less something else. However, we would argue that in providing the foundational knowledge and reasoning skills for engagement in issues relating to local and global environment and community well-being, time should be found for natural history!

In the paragraphs above, we have argued for greater inclusion of natural history within school based education and described ongoing initiatives. We have also noted that initiatives like these occur outside of the classroom under the auspices of afterschool programmes or environmental clubs (Calabrese Barton \& Tan, 2010: Carlone et al, 2015; see also Sperling \& Bencze, 2015). In the final section we consider the ways in which natural history museums, as mainstays of the informal sector, constitute an important resource for supporting natural history education.

\subsection{In the museum}

Natural history museums are important resources for natural history education due to their collection, research and education activities (Kemp, 2015; Suarez \& Tsutsui, 2004;

Sunderland et al., 2012). Firstly, museum exhibitions as the interface between the museum's visitors and its collections-based activities reflect the ongoing practices and discourses of natural history (Marandino et al., 2015). This means that they are often organised to illustrate essential natural history content such as evolutionary relationships, systematics, biodiversity, and ecosystem perspectives. This provides visiting school groups (and other learners) the opportunity to see and engage in abductive forms of reasoning that are specific to natural history. For example, Mortensen (2011) studied visitor engagement with the immersion exhibit 'Cave Expedition'. The exhibit was developed by a science centre together with two natural history museums, and focused on insect adaptations to life in permanently dark caves. Visitors who interacted with 'Cave Expedition' were subsequently able to identify the biological theme of the exhibit as well as developing interpretations of their own experiences in terms of animal adaptations to darkness. Spiegel et al. (2012), meanwhile, found that visitors to the exhibition 'Explore Evolution' were able to engage in abductive reasoning to explain evolutionary problems for living organisms more frequently than prior to their visit. 
Although it is unlikely that one interaction with an exhibit or one visit to an exhibition will prompt transformational changes in learners' understandings, the incremental changes observed in these two cases could be seen as critical steps along the educational journey of learners (see Spiegel et al., 2012). We therefore suggest that natural history exhibitions are 'windows' on natural history practices; windows that may be used to the advantage of science teachers and learners.

Secondly, museums comprise valuable repositories of rare and unique specimens indeed, natural history collections have been described as "three dimensional record[s] of the planet that sustains us" (Conniff, 2016). This means museums can offer learners opportunities to engage in authentic inquiry activities by prompting them to use scientific objects and specimens in much the same way scientists would, that is as sources of scientific interpretation and information (Bain \& Ellenbogen, 2002). For example, in a palaeontology programme conducted by a natural history museum in Denmark, Achiam et al., (2016) observed learners who were asked to compare authentic bird skeletons with realistic casts of the fossil Archaeopteryx to formulate a hypothesis of whether the extinct Archaeopteryx had been able to fly. The researchers found that not only were these learners able to formulate valid hypotheses, they also built support for these hypotheses by spontaneously engaging in palaeontologically authentic practices using the specimens in the programme. Further, the authors argued that the capability of objects to prompt scientific activity was not a characteristic specific to the palaeontological objects they observed. Rather, they suggest that a wide variety of natural history objects may afford authentic science inquiry opportunities relevant to the discipline of natural history. In fact, there is evidence to show that the more efficaciously a scientific object or specimen makes scientific processes visible or findings comprehensible, the more visitors value that object (Hampp \& Schwan, 2015).

Thirdly, as experts in the discipline and its objects, natural history museum professionals are potentially ideally placed to design exhibitions and create programmes that offer learners compelling and productive inquiry opportunities. In addition, such professionals often possess unique insights into the practices and discourses of natural history. Such insights include an understanding of how research on species, their diversity, their ecology, and their evolution contributes to our understanding of global ecosystems (Newmark \& Rickart, 2007). Engagement with these professionals, through education programmes or other activities, has the potential to promote learners' appreciation and understanding of current natural history research and its applications (Selvakumar \& Storksdieck, 2013). Furthermore, such encounters may influence students' attitudes to learning science and promote better-informed decision-making about career choices (Crowley et al., 2015; Reiss et al., 2016).

\section{Final Words}

In this article, we have sought to demonstrate the value of an education in natural history. We have joined with other commentators in highlighting the need to equip individuals and communities with the knowledge of flora and fauna, past and present, in order to understand the local and global systemic problems that we increasingly face (Tewksbury, 2014; 
Newmark \& Rickart, 2007). More specifically, we have argued that there is a need for learners to engage with forms of reasoning that extend beyond the current myopic curricula that favour the physical sciences. In particular, we have highlighted the role played by abductive, inductive and retrodictive forms of reasoning for explaining many processes in the natural world. In framing our arguments thus, our intention has been not to position natural history as an additional subject, but rather an indispensable component of science education. By similarly highlighting the application of natural history in local and global environmental and social justice initiatives, we have also sought to underscore the importance of the subject in contemporary educational practice. Finally, we have demonstrated the ways in which an education in natural history may be simply achieved in the school context and additionally supported by the resources of natural history museums. It has been suggested that the practice of natural history is a fundamental human capacity and birth-right (Fleischner, 2011). To realize this capacity and protect the birth-rights and futures of individuals, we hope that an education in natural history becomes a central component of science curricula.

\section{References}

Abrahams, I., \& Millar, R. (2008). Does practical work really work? A study of the effectiveness of practical work as a teaching and learning method in school science. International Journal of Science Education, 30(14), 1945-1969.

Achiam, M., Simony, L., \& Lindow, B. E. K. (2016). Objects prompt authentic scientific activities among learners in a museum programme. International Journal of Science Education, 38(6), 1012-1035.

Alsop, S., \& Bencze, L. (2012). In search of activist pedagogies in SMTE. Canadian Journal of Science, Mathematics \& Technology Education, 12(4), 394-408.

Amos, R. \& Reiss, M.J. (2012). The benefits of residential fieldwork for school science: Insights from a five-year initiative for inner-city students in the UK. International Journal of Science Education, 34(4), 485-511.

Arnold, S. J. (2003). Too much natural history, or too little? Animal Behaviour, 65(6), 10651068.

Aschbacher, P.R., Ing, M. \& Tsai, S.M. (2014). Is science me? Exploring middle school students' STEM career aspirations. Journal of Science Education and Technology, 23(6) 735-743.

Bain, R., \& Ellenbogen, K. M. (2002). Placing objects within disciplinary perspectives: Examples from history and science. In S. G. Paris (Ed.), Perspectives on objectcentered learning in museums (pp. 153-169). Mahwah: Lawrence Erlbaum Associates.

Balmford, A., Clegg, L., Coulson, T., \& Taylor, J. (2002). Why conservationists should heed Pokémon. Science, 295(5564): 2367.

Bartholomew, G. A. (1986). The role of natural history in contemporary biology. Bioscience, 36(5), 324-329. 
Bencze, L., Sperling, E., \& Carter, L. (2012). Students' research-informed socioscientific activism: Re/Visions for a sustainable future. Research in Science Education, 42(1), 129-148.

Bird, A. (2013). Thomas Kuhn. In E. N. Zalta (Ed.), The Stanford Encyclopedia of Philosophy (Fall 2013 Edition). Retrieved from http://plato.stanford.edu/archives/fall2013/entries/thomas-kuhn/ on January 3, 2016.

Blachowicz, J. (2009). How science textbooks treat scientific method: A philosopher's perspective. The British Journal for the Philosophy of Science, 60(2), 303-344.

Brandon, R. N. (1994). Theory and experiment in evolutionary biology. Synthese, 99(1), 5973.

Calabrese Barton, A. \& Tan, E. (2010). We be burnin': Agency, identity and learning in a Green Energy Program. Journal of the Learning Sciences, 19(2), 187-229.

Carlone, H.B., Huffling, L.D., Tomasek, T., Hegedus, T.A., Matthews, C.-E., Allen, M.H., \& Ash, M.C. (2015). 'Unthinkable' selves: Identity boundary work in a summer field ecology enrichment program for diverse youth. International Journal of Science Education, 37(10) 1524-1546.

Chawla, L.C. (1998) Significant life experiences revisited. A review of research on sources of environmental sensitivity. The Journal of Environmental Education, 29(3), 11-21.

Christian, A. \& Dzemski, G. (2007). Reconstruction of the cervical skeleton posture of Brachiosaurus brancai Janensch, 1914 by an analysis of the intervertebral stress along the neck and a comparison with the results of different approaches. Fossil Record, 10, 38-49.

Cleland, C. E. (2002). Methodological and epistemic differences between historical science and experimental science. Philosophy of Science, 69(3), 447-451.

Cleland, C. E. (2011). Prediction and explanation in historical natural science. The British Journal for the Philosophy of Science, 62(3), 551-582.

Conniff, R. (2016, April 3). Our natural history, endangered. The New York Times. Retrieved from http://www.nytimes.com

Coskie, T., Hornof, M., \& Trudel, H. (2007). A natural integration. Science and Children, 44, 26-31.

Cramp, A. (2008). Knowing me know you: Building valuable relationships outside the classroom. Education, 26(2) 171-182.

Crowley, K., Barron, B.J., Knutson, K., \& Martin, C. (2015). Interest and the development of pathways to science. In K.A. Renninger, M. Nieswandt, and S. Hidi (Eds.), Interest in mathematics and science learning and related activity. Washington, DC: AERA

Daeschler, E. B., Shubin, N. H., \& Jenkins, F. A. (2006). A Devonian tetrapod-like fish and the evolution of the tetrapod body plan. Nature, 440(7085), 757-763.

Dansgaard, W., Johnsen, S. J., Clausen, H. B., Dahl-Jensen, D., Gundestrup, N. S., Hammer, C. U., .. . Bond, G. (1993). Evidence for general instability of past climate from a 250-kyr ice-core record. Nature, 364(6434), 218-220. 
Davies, P., Sanders, D. L. \& Amos, R. (2015) Learning in cultivated gardens and other outdoor landscapes. In Boulter, C.J., Reiss, M.J \& Sanders, D.L. (Eds) DarwinInspired learning (pp 47 - 48). Rotterdam: Sense Publishers.

Dayton, P. (2003). The importance of the natural sciences to conservation. The American Naturalist, 162(1), 1-13.

Dillon, J. \& Dickie, I. 2012. Learning in the natural environment: Review of social and economic benefits and barriers. Natural England Commissioned Reports, Number 092. Natural England.

Douglas, J. A., \& Katz, C. (2009). It's all happening at the zoo: Children's environmental learning after school. Afterschool Matters, 8, 36-45.

Eberbach, C., \& Crowley, K. (2005). From living to virtual: Learning from museum objects. Curator, 48(3), 317-338.

Fisher, J. A. (2001). The demise of fieldwork as an integral part of science education in United Kingdom schools: A victim of cultural change and political pressure? Pedagogy, Culture \& Society, 9(1), 75-96.

Fleischner, T.L. (2005). Natural history and the deep roots of resource management. Natural Resources Journal, 45: 1-13.

Fleischner, T.L. (2011). Why natural history matters. The Journal of Natural History Education and Experience, 5, 21-24

Forber, P., \& Griffith, E. (2011). Historical reconstruction: Gaining epistemic access to the deep past. Philosophy \& Theory in Biology, 3, 3-19.

Futuyma, D. J. (1998). Wherefore and whither the naturalist? The American Naturalist, 151(1), 1-6.

Grandy, R.E., \& Duschl, R.A. (2005). Reconsidering the character and role of inquiry in school science: Analysis of a conference. Paper presented at the International History and Philosophy of Science and Science Teaching Group Meeting, Leeds, UK, July $15-18$.

Gray, R. (2014). The distinction between experimental and historical sciences as a framework for improving classroom inquiry. Science Education, 98(2), 327-341.

Gray, R., \& Kang, N.-H. (2014). The structure of scientific arguments by secondary science teachers: Comparison of experimental and historical science topics. International Journal of Science Education, 36(1), 46-65.

Greene, H. W. (1994). Systematics and natural history, foundations for understanding and conserving biodiversity. American Zoologist, 34(1), 48-56.

Greene, H. W. (2005). Organisms in nature as a central focus for biology. Trends in Ecology \& Evolution, 20(1), 23-27.

Greene, H. W., \& Losos, J. B. (1988). Systematics, natural history, and conservation: Field biologists must fight a public-image problem. Bioscience, 38(7), 458-462.

Gruenewald, D. A. (2003). The best of both worlds: A critical pedagogy of place. Educational Researcher, 32(4), 3-12. 
Gyllenpalm, J., Wickman, P-O. \& Holmgren, S-O. (2009) Teachers' language on scientific inquiry: Methods of teaching or methods of inquiry? International Journal of Science Education, 32(9), 1151-1172.

Halfpenny, J. C., \& Ozanne, R. (1989). Winter: An ecological handbook: Johnson Books. Hamlin, M.L. (2013). "Yo soy indígena": Identifying and using traditional ecological knowledge (TEK) to make the teaching of science culturally responsive for Maya girls. Cultural Studies of Science Education, 8(4), 759-776.

Hampp, C., \& Schwan, S. (2015). The role of authentic objects in museums of the history of science and technology: Findings from a visitor study. International Journal of Science Education, Part B, 5(2), 161-181.

Hodson, D. (2009). Teaching and learning about science. Language, theories, methods, history, traditions and values. Rotterdam: Sense Publishers

Hodson, D. (2014). Learning science, learning about science, doing science: Different goals demand different learning methods. International Journal of Science Education, $36(15), 2534-2553$.

Hutchinson, D.C (2004). A natural history of place in education. Teachers College Press: New York

Huxley, T. H. (1868). Remarks upon Archaeopteryx lithographica. Proceedings of the Royal Society of London, 16, 243-248.

Kemp, C. (2015). The endangered dead. Nature, 518(7539), 292-294.

King, H. (2009) Supporting natural history inquiry in an informal setting: A study of museum explainer practice. Unpublished $\mathrm{PhD}$ thesis, King's College London.

Kuhn, T. S. (1977). The essential tension. Selected studies in scientific tradition and change. Chicago: University of Chicago Press.

Ladson-Billings, G. (1995). Towards a theory of culturally relevant pedagogy. American Education Research Journal, 32(3), 465-491.

Lamont, E., Jeffes, J., and Lord, P. (2010). Evaluation of the nature and impact of the Creative Partnerships Programme on the teaching workforce: Final Report. Slough: NFER.

Lawson, A.E. (2010). Basic inferences of scientific reasoning, argumentation, and discovery. Science Education, 94, 336-364.

Lewontin, R. (2002). The triple helix: Gene, organism, environment. Cambridge: Harvard University Press.

Lorsbach, A., J. Jinks. (2013). What early 20th century nature study can teach us. Journal of Natural History Education and Experience 7, 7-15.

Louv, R. 2006. Last child in the woods: Saving our children from nature-deficit disorder. Algonquin Books, Chapel Hill.

Malone, K. and Waite, S. (2016) Student outcomes and natural schooling. Plymouth: Plymouth University. Available online: http://www.plymouth.ac.uk/research/oelres-net Marandino, M., Achiam, M., \& Oliveira, A. D. (2015). The diorama as a means for biodiversity education. In S. D. Tunnicliffe \& A. Scheersoi (Eds.), Natural history 
dioramas - History, construction and educational role (pp. 251-266). Dordrecht: Springer.

Maxwell, J.A. (2004). Causal explanation, qualitative research, and scientific inquiry in education. Educational Researcher, 33(2) 3-11.

Mayr, E. (2004). What makes biology unique? Considerations on the autonomy of a scientific discipline. New York: Cambridge University Press.

Miller, J. R. (2005). Biodiversity conservation and the extinction of experience. Trends in Ecology \& Evolution, 20(8), 430-434

Mortensen, M. F. (2011). Analysis of the educational potential of a science museum learning environment: Visitors' experience with and understanding of an immersion exhibit. International Journal of Science Education, 33(4), 517-545.

Newmark, W. D., \& Rickart, E. A. (2007). Are natural history museums telling the right story? Bioscience, 57(5), 390-390.

NGSS. 2013. Next Generation Science Standards: For States, by States. Washington, DC: The National Academies Press.

Nundy, S. (1999). The fieldwork effect: the role and impact of fieldwork in the upper primary school. International Research in Geographical and Environmental Education 8(2), 190-198.

Orion, N., \& Hofstein, A. (1994). Factors that influence learning during a scientific field trip in a natural environment. Journal of Research in Science Teaching, 31(10), 10971119.

Peacock, A. (2006). Changing minds: The lasting impact of school trips. The Innovation Centre, University of Exeter.

Pergams, O. R. W., \& Zaradic, P. A. (2006). Is love of nature in the U.S. becoming love of electronic media? 16-year downtrend in national park visits explained by watching movies, playing video games, internet use, and oil prices. Journal of Environmental Management, 80, 387-393.

Pergams, O. R. W., \& Zaradic, P. A. (2008). Evidence for a fundamental and pervasive shift away from nature-based recreation. Proceedings of the National Academy of Sciences, $105,2295-2300$.

Piranha, J. M., Aparecida Del Lama, E., \& de La Corte Bacci, D. (2011). Geoparks in Brazil-strategy of geoconservation and development. Geoheritage, 3(4), 289-298.

Redi, F (1688/1909). Experiments of the generation of insects. (M. Bigelow, trans.). Chicago: Open Court Publishing Company.

Reiss, M., Billingsley, B., Evans, E. M., Kissel, R. A., Lawrence, M., Munro, M., . . Veall, D. (2016). The contribution of natural history museums to science education. Phase 1 Planning Grant Report: Science Learning+ Programme.

Rideout, V. J., Foehr, U. G., \& Roberts, D. F. (2010). Generation M2: Media in the lives of 8-18-year-olds. Menlo Park: Henry J. Kaiser Family Foundation

Rose, S. (2005). Lifelines: Life beyond the gene. London: Vintage. 
Rudolph, J.L. \& Stewart, J. (1998). Evolution and the nature of science: On the historical discord and its implications for education. Journal of Research in Science Teaching 35(10), 1069-1089.

Schopf, J.W. (2000). Solution to Darwin's dilemma: Discovery of the missing Precambrian record of life. Proceedings of the National Academy of the Sciences 97(13), 69476953.

Selvakumar, M., \& Storksdieck, M. (2013). Portal to the public: Museum educators collaborating with scientists to engage museum visitors with current science. Curator, 56(1), 69-78.

Sobel, D. (2008). Children \& nature: Design principles for educators. Portland: Stenhouse Publishers.

Sperling, E., \& Bencze, L. (2015). Reimagining non-formal science education: A case of ecojustice-oriented citizenship education. Canadian Journal of Science, Mathematics \& Technology Education, 15(3), 261-275.

Spiegel, A. N., Evans, E. M., Frazier, B., Hazel, A., Tare, M., Gram, W., \& Diamond, J. (2012). Changing museum visitors' conceptions of evolution. Evolution: Education and Outreach, 5(1), 43-61.

Stevens, K.A. \& Parrish, J.M. (1999). Neck posture and feeding habits of two Jurassic sauropod dinosaurs. Science, 284, 798-800.

Suarez, A. V., \& Tsutsui, N. D. (2004). The value of museum collections for research and society. Bioscience, 54(1), 66-74.

Sunderland, M. E., Klitz, K., \& Yoshihara, K. (2012). Doing natural history. Bioscience, 62(9), 824-829.

Taber, K. S. (2013). Methodological issues in science education research: A perspective from the philosophy of science. In M. R. Matthews (Ed.), International Handbook of Research in History, Philosophy and Science Teaching (pp. 1839-1893). Dordrecht: Springer.

Taylor, M.P., Wedel, M.J., \& Naish, D. (2009). Head and neck posture in sauropod dinosaurs inferred from extant animals. Acta Palaeontologica Polonica, 54(2), 213-220.

Tewksbury, J.J., Anderson, J. G.T., Bakker, J.D., Billo, T. J., Dunwiddie, P.W., . . Wheeler, T.A. (2014). Natural history's place in science and society. BioScience, 64(4), 300310.

Tiberghien, A. (2000). Designing teaching situations in the secondary school. In R. Millar, J. Leach, \& J. Osborne (Eds.) Improving science education: The contribution of research (pp. 27-47). Buckingham, UK: Open University Press.

Trombulak, S.C., and T.L. Fleischner. 2007. Natural history renaissance. Journal of Natural History Education 1: 1-4.

Wals, A. E. J., Brody, M., Dillon, J., \& Stevenson, R. B. (2014). Convergence between science and environmental education. Science, 344(6184), 583-584.

Watson, B., \& Werb, S. R. (2013). One hundred strong: A colloquium on transforming natural history museums in the twenty-first century. Curator: The Museum Journal, 56(2), 255-265. 
This is the pre-print version of the manuscript published as King, H., \& Achiam, M. (2017). The case for natural history. Science \& Education, 26(1), 125-139. The final publication is available at Springer via http://dx.doi.org/10.1007/s11191-017-9880-8

Wilcove, D. S., \& Eisner, T. (2000). The impending extinction of natural history. Chronicle of Higher Education, 15, B24.

Windschitl, M. (2002). The reproduction of cultural models of inquiry by pre-service teachers: An examination of thought and action. Proceedings of the International Conference of the Learning Sciences, 2002.

Windschitl, M. (2003) Inquiry projects in science teacher education: What can investigative experiences reveal about teacher thinking and eventual classroom practice? Science Education, 87(1), 112-143. 